\title{
Stable individual differences on developmental tasks in young yellow-crowned parakeets, Cyanoramphus auriceps
}

\author{
MILDRED S. FUNK and RANA L. MATTESON \\ Northwestern University, Evanston, Illinois
}

\begin{abstract}
We report on stable individual differences in young yellow-crowned parakeets across 38 tasks of cognitive development on three scales involving object permanence, means-end relations, and spatial relations. Stable performance ranks on blocks of tasks emerged after 13 weeks in two groups of sibling parakeets, one hand-reared and the other parent-reared. Examination of subject characteristics, such as hatch order, sex, general activity level, avoidances, latencies, social status, and errors, showed no significant correlations with these performance ranks. Characteristic individual approaches to unstructured play activities (from a fourth scale) were consistent with individual behavioral differences seen on the structured cognitive tasks.
\end{abstract}

Intraspecific individual differences in behavior have been extensively described in human and nonhuman primates and other mammals, but there have been fewer reports on such variation in other classes of vertebrates, such as birds (Beauchamp, 2000). Avian studies that have described individual differences have reported on variation in personality traits in adult zebra finches (Figueredo, Cox, \& Rhine, 1995) and juvenile great tits (Drent, van Oers, \& van Noordwijk, 2003); exploratory behavior in jackdaws (Katzir, 1982); feeding habits in American robins (Jung, 1992) and oystercatchers (Norton-Griffiths, 1967); vocalizations such as distress screams in starlings (Chaiken, 1992), songs and calls in a variety of monogamous or colonially living species (Falls, 1982), coos in collared doves, (ten Cate, 1992), and booms in bitterns (McGregor \& Byle, 1992).

Although such individual variation has been little reported outside of humans and other primates, it is extremely important in nature because natural selection operates upon just such individual differences within a population (Slater, 1981). Intraspecific individual differences impact sexual selection, breeding success, group dynamics, use of territory, predator avoidance, foraging, and resource use; hence, they affect a range of survival and conservation issues.

The present article describes the emergence of stable individual differences in two groups of young yellow-

Testing of subjects was done at Northwestern University for the doctoral dissertation of M.S.F. She thanks Irene Pepperberg and Donald Sade for permitting housing of the birds in lab space and for their helpful suggestions. She also thanks Lois Sears for assisting in the testing and for filming portions of it. We appreciate the reviewers' valuable comments on the manuscript. Correspondence should be addressed to M. Funk, Biology Department, Roosevelt University, 430 S. Michigan Ave., Chicago, IL60605 (e-mail: mdfunk@northwestern.edu or mfunk@roosevelt.edu). crowned parakeets on 38 developmental tasks that have cognitive and motor components (see the Appendix). Two groups of siblings were tested, one hand-reared and the other parent-reared. Tasks were from three Piagetian scales (listed in Uzgiris \& Hunt, 1989) that have been widely used to assess development in human infants. Use of the scales allowed testing of both individual differences and various aspects of cognition in the birds in a standardized way, and use of siblings allowed us to show the variation that can exist within a family group. Subjects performed the tasks spontaneously, in accord with Piagetian protocol. Results of the two groups' task performance have been reported in several articles, on the subjects of object permanence (Funk, 1996a), spatial relations (Funk, 1996b), and means-end understanding (Funk, 2002). The topic of this study, the birds' emerging individual consistency in rank order on task performance, was observed across different types of tasks from a fledging state at 6 weeks to maturity at about 8 months. Their performance was consistent across the three scales; one of the scales (object permanence) was declarative in orientation, allowing them to make right or wrong answers, whereas the other two scales were procedural, focusing on whether or not they could perform a task. Comparisons across procedural and declarative aspects of performance allowed assessment of the stability and generalization of individual differences.

The Piagetian tasks (Piaget, 1953, 1954), targeted originally for human infants below 2 years of age, have been used extensively to test cognitive development in nonhuman primates and other mammals (Doré \& Dumas, 1987; Tomasello \& Call, 1997; Vauclair, 1996). These sensorimotor activities show how young subjects first begin to react to objects and gather information about their surroundings. For instance, the scales focus not just on the earliest evidence of walking, but rather on walking to at- 
tain some object; not on seeing, but on using vision to follow the trajectory of an object and note its disappearance. Such activities, attaining objects and following trajectories, are also common in young birds in the wild. In fact, many of these tasks are also biologically relevant to development in the wild for many avian species, because the more complex skills impact food gathering, exploring, playing with and learning about novel objects, finding others, making detours, and other common activities for the young. Of course, not all the tasks resemble activities that might be in the repertoire of nonhuman animals, and comparative testing may heuristically find not only these differences, but also hitherto unrecognized abilities in other species. The object permanence tasks, in particular, can be used to assess not only which species have particular abilities, but also the quality of attention of those species (Pepperberg \& Funk, 1990). Such a broadly adaptable protocol is helpful, then, in comparative testing.

The natural history and abilities of a species can suggest its cognitive potential on comparative testing. For instance, Diamond (1987) has suggested that birds living in rich, tropical forests may be selected for specialized learning abilities useful to locate resources. New Zealand parakeets, for instance, live in a temperate rain forest, forage for a wide number of plant species (about 90), and are very persistent, attentive, and "systematic" in their search for concealed insects (Greene, 1988). These parakeets are flexible as well, able to live in a range of habitats and on a variety of foods (Taylor, 1985). The birds in the present study were active and prone to explore and manipulate as subjects. In previous studies (Funk, 1996a, 1996b, 2002), the parakeets did well on the tasks given them, performing successfully on 33.5 out of 38 tasks in the three scales (they failed to stack objects or fill containers).

In this article, we analyze individual differences noted in task performance and assess when the differences emerged in the young subjects. We also examine subject characteristics, such as hatch order, sex, activity level, latencies, avoidances, social status, and errors, to see if any of these factors correlated with the performance ranks. Two activities were also administered from a fourth scale (Scale IV; Uzgiris \& Hunt, 1989) involving unstructured play with novel objects. We introduced these final activities to see whether the individual patterns of behavior apparent in the other three scales were artifacts related to structured testing (possibly somewhat aversive to some of the subjects) or were more generalized individual responses that would also emerge in a free-play situation.

\section{METHOD}

\section{Subjects}

Much of the information in this section reports details of the testing methods already described in three previous articles (Funk, 1996a, 1996b, 2002).

Eleven yellow-crowned parakeets of New Zealand (commonly called "kakariki") were tested on 38 sensorimotor activities from ages 4 weeks to 32 weeks. Six of the 11 parakeets were parent- reared in a laboratory at Northwestern University. Five others from a later brood (same parents) were removed from the parents at 2-4 weeks of age and were then partly reared by "Kiri," an unrelated female kakariki, and partly hand-reared by the principal investigator. The first group included 2 females, 3 males, and an additional male with minor problems in fine motor control; the second group included 2 females, 2 males, and another male who had minor impairment in movement. Impairments of the 2 disadvantaged birds had been noted when they were fledglings and were later noticeable only sometimes during testing. They accommodated well to life in their home cage and were among the more active, vocal individuals.

Every few days starting at 4-5 weeks, the parent-reared birds were removed from the nest box and quietly spoken to while being gently handled, in order to accustom them to the investigator. The hand-reared birds were taken out of the nest box and were observed starting at 4 weeks of age on tasks such as the slow trajectory and glancing around to locate sound. Because they were accustomed to handling, they were able to settle down and start work on the tasks earlier, and thus were analyzed in a separate group.

\section{Diet and Housing}

The birds were fed a diet of mixed parakeet and parrot seeds, fresh fruits and vegetables, and water with a vitamin supplement. On testing days, they were not offered their preferred seeds (safflower and sunflower) so that these could be used as rewards. Food and lighting were the same for all subjects.

Both groups of birds were removed at 6 weeks into flight cages $(77 \times 77 \times 36 \mathrm{~cm})$ with hanging toys (rawhide strips and colored rings). The parent-reared group were caged apart from their parents after fledging but were housed in the same room with them. The hand-reared group were housed together with one another but apart from Kiri, the unrelated kakariki who had earlier fed them; usually, though, they were still in the same room with her.

\section{Testing Environment and Search Items}

The birds in both groups were tested individually in the same two testing cages $(40 \times 40 \times 50 \mathrm{~cm}$ and $61 \times 51 \times 38 \mathrm{~cm})$. Lighting, search items, manipulatives, and testing procedures were the same for all subjects.

Objects used in testing the object permanence scale were small napkin pieces $(6 \times 6 \mathrm{~cm})$ to hide food rewards (seeds or pieces of fruits) and small candy cups or a coffee scoop for transferring the reward item. For the means-end scale, the same food rewards and paper pieces were used. Other test items were elastic string or rawhide strips $(12-18 \mathrm{~cm})$, sticks and T-sticks $(12-20 \mathrm{~cm})$, and a small matchbox. For the spatial relations scale, plastic keys, bottle caps, and the candy cups were used in addition to the following items $(3-6 \mathrm{~cm})$ : a small mirror and a round disk with a silver (reflecting) surface on one side, a small plastic ball with a bell inside, and colored plastic bottle caps. For the unstructured play, we provided the small toys $(3-8 \mathrm{~cm})$ that Uzgiris and Hunt (1989) suggested to interest human infants: a small rabbit toy (operated by a string, with arms and legs that could be moved by pulling the string), a mechanical wind-up rabbit, two roly-polys (one with a mirror on top), a small penguin on wheels, a small blue top, and a green top with a bell inside.

\section{Tasks}

Scale I: Object permanence. Object permanence tasks test search skills and visual tracking. Tasks 1 and 2 involved visually following colored yarn in a slow trajectory and noting its disappearance. In Tasks 3-9, reactions to hiding procedures were measured, with subjects directly observing the object being hidden (visibly displaced). In Tasks 10-15, the reward was invisibly displaced from a container or hand, and the empty container (or hand) was then shown to the subject so that the investigator could see whether 
the subject could infer the new location of the object. In the first two visible displacements, a small piece of apple or grape was partly covered (Task 3), then fully covered (Task 4), under a piece of napkin. Tasks 5 and 6 were presented together: A few seeds were hidden in one of two places (Task 5), and then the two hiding locations were alternated (Task 6). In Task 7, seeds were hidden in one of three places; in Task 8 , the seed reward was shown being moved between the three places and then hidden. Overlapping covers (small candy cups and napkin pieces) were the hiding locations for seeds in Task 9, testing for perseverance in removing the multiple covers as well as approach to a novel object, the candy cups. In Tasks $10-15$, a few seeds placed in a small coffee scoop were shown to the subject, then covered while the cup was surreptitiously emptied under one cover (Task 10), then under one of two covers (Task 11), then under one of two covers that were alternated (Task 12), and finally under one of three covers (Task 13). In Task 14, the seeds were hidden in the investigator's hand, the hand was moved between three covers, and the seeds were placed surreptitiously under the last cover. In Task 15, the investigator either did not hide the seeds under any cover, or displaced the seeds hidden in her hand under the first cover but continued to move her hand between the other covers, pausing at them as in the previous task. This task tested for odor cues.

Scale II: Means-end. Functional understanding of causal relationships was evaluated using the means-end tasks. Initial activities were hand (claw)-watching (Task 1), grasping a seen object (Task 2), playing with objects such as rawhide strings or colored rings (Task 3), letting go of one object to reach for another (Task 4), and locomotion as means to obtain an object (Task 5). For Task 6, a small napkin piece was placed in the front edge of the cage tray, which had been pulled out in front of the cage so that the subject could reach the edge of the napkin. In Task 7, two napkin pieces were presented side by side, only one of which had seeds on it. This situation tested whether the subject had a functional understanding that by pulling on the appropriate napkin piece, she would obtain seeds. Tasks 6 and 7 were tested together, because both tested awareness of the support relationship. When an empty support is set in front of a subject (as directed in the original version of Task 7), it is difficult for any subject to restrain a tendency to pull in a support piece even though it is empty. Uzgiris (1987, p. 151) discussed this problem and suggested that a "better assessment situation" needed to be designed for Task 7. The protocol used in this experiment (and also in Mathieu, Daudelin, Dagenais, \& Decarie, 1980) is adequate to demonstrate the understanding of a support relationship. For Task 8, elastic strings or rawhide strips with pieces of apple or grape were positioned at the front of the cage tray, which was again pulled out in front of the cage. In Task 9, the strings with the rewards on the end were hung vertically from the cage bars. An apron around the bottom of the cage kept the birds from simply reaching the hanging reward through the bars. Because of either the birds' difficulties with the tasks or procedural errors, Tasks 10-12 had to be eliminated from the analysis.

Scale IV: The development of operational causality. The seven activities on this scale repeat several tasks from other scales, assess game playing abilities, and include two activities involving play with common toys. We used the latter two activities: 6. "Behavior to a spectacle created by an agent acting on an object" and 7. "Behavior to a spectacle created by a mechanical agent." For Task 6, small tops, roly-polys, a small figure on wheels, and a rabbit with arms and legs that could be operated by strings were demonstrated for the birds, and for Task 7, the mechanical rabbit was demonstrated for them.

Scale V: Spatial relations. The ability to assess spatial relationships among objects was measured on this final scale. Subjects glanced between objects (Task 1), located objects by sound (Task 2), and grasped objects under visual guidance (Task 3). Task 4 involved visually following objects along a rapid trajectory. Task 5 required reversing objects (turning around small mirrors) to see the reflecting side. In Task 6 , containers (small candy cups) were to be filled and emptied of seeds. Task 7 consisted of balancing blocks on each other. Small styrofoam blocks were sprayed with bitter apple so the birds would not try to eat them. Because the birds did not attempt Task 7, another Piagetian task at the same level of difficulty was substituted that also tested balancing and maneuvering: For this task, the birds manipulated 13- to 18-cm twigs suspended on elastic string through the bars of the cage (Piaget tested this activity when his 15 -month-old subjects were in playpens). In Task 8 , subjects were to raise and lower strings with small balls on the ends (as seen in a film on the tasks: Uzgiris \& Hunt, 1967). Because of procedural errors, Tasks 9 and 11 were not included in the analysis. Detour behavior was measured on Task 10: We used four types of increasingly difficult detours: (1) a large wastebasket $(38 \times 35 \mathrm{~cm})$, (2) two cushions $(46 \times 62 \mathrm{~cm}),(3)$ two transparent plastic screens $(56 \times 56 \mathrm{~cm})$, and $(4)$ a tall white wooden room divider with four panels that formed a cul-de-sac.

\section{Procedure}

There was no pretraining on any tasks, since they were presented to investigate the spontaneous reactions and the natural abilities of the young birds. Sessions were $20-40 \mathrm{~min}$ long, depending on the attention and cooperation of the subjects. Each scale had a minimum number of three sessions per task (see the Appendix for the number of trials involved in each task). However, in some cases, individuals required additional sessions to reach criterion due to their errors (Scale I), avoidances, or mistrials.

Testing for each of the birds was distributed across morning and afternoon sessions. Usually three tasks from different scales were presented in a session. One of two persons presented the tasks, observing and recording the results; at times, the other person videotaped a sample of the responses. Tasks were presented in scale order (to see whether the birds would follow that order), except for a few random probes such as the detour task (Scale V, Task 10). When a subject (who was not obviously tired or fearful of a novel object) failed to approach a new task, a familiar task was presented to check for motivation to work. If the familiar task was not performed, the session was discontinued. If the familiar task was performed, then a more advanced task was presented to probe for scale ordinality. If correctly performed, the task would be repeated for the required number of trials, usually a total of three (see the Appendix). Exploration of a novel object, play, or failure to approach the task within the allotted time were treated as mistrials or avoidances. The latter reactions plus errors on the object permanence scale allowed differences in rates of progress to emerge among the birds.

\section{Measures and Analyses}

The primary dependent measure of performance on tasks from the three scales was the age at criterion - that is, each bird's first correct session that was followed by a second correct session (Funk, 1996a). Age at criterion for each task was then converted to rank order within each of the two groups to evaluate stability of individual differences in performance.

Seven subject characteristics were assessed: (1) Each bird's hatch order and (2) sex were noted. (3) Errors were recorded on object permanence Tasks 3-15 but not on tasks from the other scales, because those other tasks offered little opportunity for error. Rather than accuracy, the measure on the other scales was simply completion of the task; for example, did a subject pull in the string or not? (4) Activity level in the home cage was measured in contrast to inactivity, which could emerge in forms such as staring, clinging to the side of the cage, resting, or sitting. Twenty hours of observation were gathered over a 3-month period for each group to see whether general activity level varied among individuals. (5) Latency, the time from presentation to approach of an the activity, was filmed and analyzed on random tasks in each scale for each subject. 
Table 1

Mean Age Rank at Criterion on Final Block of Tasks on Three Developmental Scales

\begin{tabular}{ccccc}
\hline \multirow{2}{*}{ Rearing } & Bird ID & $\begin{array}{c}\text { Scale I } \\
\text { Object Permanence }\end{array}$ & $\begin{array}{c}\text { Scale II } \\
\text { Means-End }\end{array}$ & $\begin{array}{c}\text { Scale V } \\
\text { Spatial Relations }\end{array}$ \\
\hline Parent-reared & P1 & 4 & 4 & 4 \\
& P2 & 6 & 6 & 6 \\
& P3 & 5 & 2 & 5 \\
& P4 & 3 & 1 & 3 \\
& P5 & 2 & 3 & 1 \\
$W$ & P6 & 1 & 5 & 2 \\
$d f$ & & .883 & .392 & .499 \\
$p$ & & $6,5)$ & $(6,6)$ & $(6,5)$ \\
Hand-reared & H7 & $<.01$ & $<.05$ & $<.05$ \\
& H8 & 5 & 5 & 5 \\
& H9 & 2 & 3 & 4 \\
& H10 & 3 & 4 & 2 \\
$W$ & H11 & 1 & 2 & 3 \\
$d f$ & & .904 & 1 & 1 \\
$p$ & & $(5,5)$ & .831 & .696 \\
& & $<.01$ & $(5,6)$ & $(5,5)$ \\
\hline
\end{tabular}

Note- $W$, Kendall's rank-order correlation coefficient.

Table 2

Stability of Rank Orders on Blocks of Tasks for Scale I (Object Permanence), Scale II (Means-End), and Scale V (Spatial Relations)

\begin{tabular}{|c|c|c|c|c|c|c|c|c|}
\hline \multirow[b]{2}{*}{ Rearing } & \multirow[b]{2}{*}{ Bird ID } & \multicolumn{3}{|c|}{ OP } & \multicolumn{2}{|c|}{ ME } & \multicolumn{2}{|c|}{ SR } \\
\hline & & I & M & $\mathrm{F}$ & I & $\mathrm{F}$ & I & $\mathrm{F}$ \\
\hline \multirow[t]{5}{*}{ Parent-reared } & P1 & 4 & 5 & 3 & 3 & 4 & 4.5 & 3 \\
\hline & P2 & 5 & 4 & - & 5 & 5 & 2 & 5 \\
\hline & P3 & 3 & 3 & 4 & 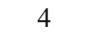 & 2 & 4.5 & 4 \\
\hline & P4 & 1 & 1 & 2 & 1 & 1 & 1 & 2 \\
\hline & P5 & 2 & 2 & 1 & 2 & 3 & 3 & 1 \\
\hline$W$ & & .648 & .736 & .917 & .679 & .838 & .163 & .671 \\
\hline$d f$ & & $(5,5)$ & $(5,5)$ & $(5,5)$ & $(5,4)$ & $(5,4)$ & $(5,4)$ & $(5,5)$ \\
\hline$p$ & & $<.01$ & $<.01$ & $<.01$ & $<.05$ & $<.01$ & n.s. & $<.01$ \\
\hline Mean final age, weeks & & 17.9 & 23.5 & 29.3 & 7.8 & 13.4 & 9.1 & 18.2 \\
\hline$S D$ final age & & 0.589 & 2.098 & 1.715 & 1.342 & 1.095 & 0.763 & 0.773 \\
\hline \multirow[t]{4}{*}{ Hand-reared } & $\mathrm{H} 7$ & 4 & 4 & 4 & 4 & 4 & 4 & 4 \\
\hline & H9 & 3 & 3 & 2 & 2 & 3 & 1.5 & 2 \\
\hline & H10 & 2 & 2 & 3 & 1 & 2 & 3 & 3 \\
\hline & H11 & 1 & 1 & 1 & 3 & 1 & 1.5 & 1 \\
\hline$W$ & & .392 & .808 & .904 & .175 & .925 & .327 & .744 \\
\hline$d f$ & & $(4,5)$ & $(4,5)$ & $(4,5)$ & $(4,4)$ & $(4,4)$ & $(4,4)$ & $(4,5)$ \\
\hline$p$ & & n.s. & $<.01$ & $<.01$ & n.s. & $<.01$ & n.s. & $<.01$ \\
\hline Mean final age, weeks & & 13.2 & 22.1 & 28.3 & 7.8 & 12.9 & 11.0 & 20.3 \\
\hline$S D$ final age & & 1.509 & 1.852 & 2.601 & 0.860 & 0.820 & 4.012 & 8.208 \\
\hline
\end{tabular}

Note-OP (object permanence): I (initial), Tasks 1-5; M (middle), Tasks 9, 6, 10-12; F (final), Tasks 7, 8, 13-15. ME (means-end): I, Tasks 5, 3, 4, and 2; F, Tasks 6-9. For Tasks 10, 11, and 12, see task descriptions. SR (spatial relations): I, Tasks 1-4; F, Tasks $6,5,10,7$, and 8 . For Tasks 9 and 11, see task descriptions.

(6) Avoidances were counted when subjects failed to react in a session. Initial tasks on the three scales were not included in this analysis, because subjects at that point were too young to pay attention, making it difficult to reliably assess them on these simple activities. (7) Finally, we ranked the birds on their social status. Alpha status was represented by the dominant male in each group and the female in each group who maintained proximity with the alpha male and who displayed dominance over the other females in her group, as manifested by priority in place and feeding.

We used the Kendall coefficient of concordance to test stability of age ranks of the birds at criterion on 38 tasks. This test measures the relation among a set of rankings of a group of objects or individuals (Siegel \& Castellan, 1988, p. 262). Spearman's rank-order correlations $\left(r_{\mathrm{s}}\right)$, phi coefficient test $\left(r_{\phi}\right)$, Fisher's exact test, Fried- 
man's chi-square test $\left(\chi_{\mathrm{r}}^{2}\right)$, and analyses of variance (ANOVAs) were used to evaluate other relations among subject characteristics.

\section{RESULTS}

Analyses were conducted independently on the ages at criterion for the parent-reared (PR: $n=6$ ) and handreared (HR: $n=5$ ) birds using Kendall coefficients of concordance. For the final block of tasks on each of the three cognitive scales, each group of birds showed significantly stable mean rank orders of age at criterion (see Table 1). Two birds, 1 from each group, were excluded from subsequent analyses (see Table 2) due to impaired foot use, which added considerable variability to their performance. (Analyses including these birds did show similar patterns of significance to those seen with the core birds, but sometimes at a lower level, for example, at $p<.05$ instead of $<.01$.) Although the final ranks were not identical across the three scales, for the PR group they were significantly correlated according to a Kendall coefficient of concordance $[W(5,3)=.778, p<.05]$. For the HR group, it was not possible to directly confirm statistical significance with such a small sample using a Kendall test. However, in accordance with Zar (1984, pp. 355, 567), a conversion to a Friedman's chi-square statistic indicated a significant correlation of final ranks across the three scales $\left(\chi_{\mathrm{r}}^{2}=8.199, p<.05\right)$. The analysis of the core birds alone (excluding the 2 impaired birds) showed an increase in the statistical stability of final rank orders, as seen in Table 2. A significant increase in the differentiation between ranks was verified by repeated measures ANOVAs for each scale, as stated below.

\section{Scale I. Object Permanence}

Table 3 shows performance for the 9 core birds on the set of 15 object permanence tasks. Across the set of 15 tasks, the birds in each group showed significantly stable rank orders in age at criterion [Kendall coefficient of concordance: PR, $W(5,15)=.393, p<.01 ; \mathrm{HR}, W(4,15)=$ $.630, p<.01]$. Examination of ranks by blocks of tasks showed the emergence of these stable individual differences over 3 months of age (see Table 2).

Figure 1 illustrates the increasing stability (i.e., less variability) of the birds' ranks over time. Two $2 \times 2$ mixed ANOVAs indicated significant reductions in the range of ranks over time [initial vs. final block, $F(1,7)=$ $10.234, p=.015$; middle vs. final block, $F(1,7)=13.244$, $p=.008]$.

\section{Scale II. Means-End}

In order to examine stability of individual differences in performance ranks over time, the tasks were divided into two blocks according to the mean order of task completion, which although not identical for the two groups, divided clearly between the early developmental tasks and the later, more complex tasks. Although ranks were not identical for each block, there was significant concordance across ranks on the entire set of eight tasks [Kendall coefficient of concordance: PR, $W(5,8)=.598, p<.01 ; \mathrm{HR}, W(4,8)=.361$, $p<.05]$. The individuals in both groups showed significant stability of ranks on the final blocks (see Table 2), which contrasts with the greater instability of ranks in the initial blocks of tasks. The increasing stability of the birds' ranks over time is also seen in Figure 2 [ANOVA, $F(1,7)=$ $5.095, p=.059]$.

\section{Scale V. Spatial Relations}

Again, there was a statistically significant stability of ranks across the entire set of nine spatial relations tasks [Kendall coefficient of concordance: PR, $W(5,9)=.254$, $p=.05$; HR, $W(4,9)=.503, p<.01]$. Both groups showed significant stability of ranks in age at criterion

Table 3

Mean Age at Criterion in Weeks on Scale I, Object Permanence

\begin{tabular}{|c|c|c|c|c|c|c|c|}
\hline \multirow[b]{2}{*}{ Task } & \multirow[b]{2}{*}{ Description } & \multicolumn{2}{|c|}{$\begin{array}{l}\text { Parent Reared } \\
\qquad(n=5)\end{array}$} & \multicolumn{2}{|c|}{$\begin{array}{l}\text { Hand Reared } \\
\qquad(n=4)\end{array}$} & \multirow[b]{2}{*}{$t_{7}$} & \multirow[b]{2}{*}{$p$} \\
\hline & & $M$ & $S D$ & $M$ & $S D$ & & \\
\hline 1 & Trajectory & 7.9 & 0.566 & 5.6 & 0.297 & 7.110 & .000 \\
\hline 2 & Disappearance & 9.0 & 1.022 & 7.7 & 0.841 & 2.065 & .078 \\
\hline 3 & Partial cover & 10.3 & 1.147 & 8.5 & 0.768 & 2.708 & .030 \\
\hline 4 & Complete cover & 16.1 & 2.160 & 10.3 & 1.071 & 4.859 & .002 \\
\hline 5 & Two-place locate & 17.9 & 0.589 & 13.2 & 1.509 & 6.436 & .000 \\
\hline 9 & Superposition & 19.3 & 0.911 & 15.4 & 0.728 & 6.913 & .000 \\
\hline 6 & Alternate place & 20.2 & 2.683 & 15.9 & 1.445 & 2.826 & .026 \\
\hline 10 & Invisible displacement & 20.2 & 1.007 & 17.4 & 1.218 & 3.709 & .008 \\
\hline 11 & Two invisible displacements & 22.7 & 1.484 & 20.8 & 2.029 & 1.655 & n.s. \\
\hline 12 & Alternating invisible displacements & 23.5 & 2.098 & 22.1 & 1.852 & 0.981 & n.s. \\
\hline 7 & Three-place locate & 26.6 & 2.529 & 24.6 & 1.818 & 1.324 & n.s. \\
\hline 8 & Visible displacements, three-place & 26.7 & 1.321 & 26.9 & 2.980 & 0.146 & n.s. \\
\hline 13 & Invisible displacements, three-place & 28.2 & 1.668 & 26.7 & 1.545 & 1.403 & n.s. \\
\hline 14 & Invisible displacement series & 29.3 & 1.715 & 28.3 & 2.734 & 0.631 & n.s. \\
\hline 15 & Reverse order search & 29.3 & 1.715 & 28.3 & 2.601 & 0.701 & n.s. \\
\hline
\end{tabular}

Note-Ages for human infants are given in Uzgiris and Hunt (1989, pp. 105-121). See the Appendix for detailed task descriptions. 

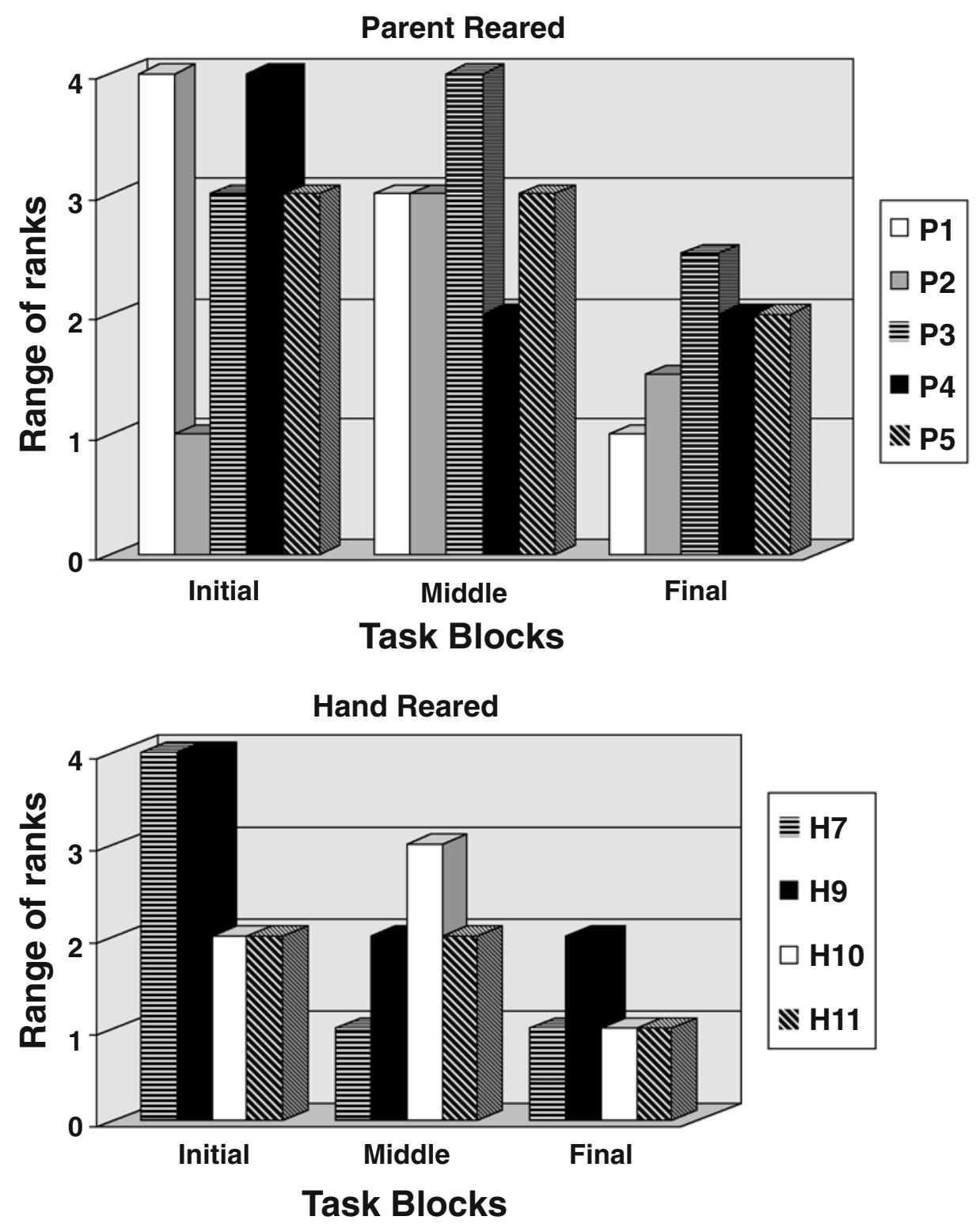

Figure 1. Scale I, object permanence: Range of rank orders on blocks of tasks.

on the final block of tasks (see Table 2), which contrasts with the absence of stable ranks in the initial block for each group. Figure 3 also shows the greater stability of ranks on the final block of tasks [ANOVA: $F(1,7)=$ $6.721, p=.036]$.

\section{Subject Characteristics}

Rank orders based on hatch order, sex, activity level, latencies, avoidances, social status, and errors did not show significant association with the stable rank orders of the cognitive scales according to Spearman's rank-order correlations, all $p \mathrm{~s}>.05$.

Hatch order. The identifying numbers for the birds are arranged in chronological (or hatch) order. As can be seen in Table 1, even though the final rank order was often similar to the age (hatch order), it is not identical. The PR birds began the tasks when they emerged from the nest box; thus, all of them were at about the same age when they began the testing. The HR birds began when a few early tasks were tried at around 4 weeks; thus, they were also about the same age as they began testing. Table 2 and Figures 1, 2, and 3 show that rank orders on the initial blocks were quite variable, and thus not solely determined by hatch order. Also, the range of the criterion ages on the final task (PR, $25 \mathrm{~d}$; HR, $43 \mathrm{~d}$ ) exceeded the range at task outset (PR, $8 \mathrm{~d}$; HR, $8 \mathrm{~d}$ ), which allowed room for movement in ranks.

Avoidance behaviors and social status. Three individuals, $\mathrm{P} 2, \mathrm{P} 3$, and $\mathrm{H} 7$, as well as the two impaired birds, showed above average avoidance behaviors. It was un- 

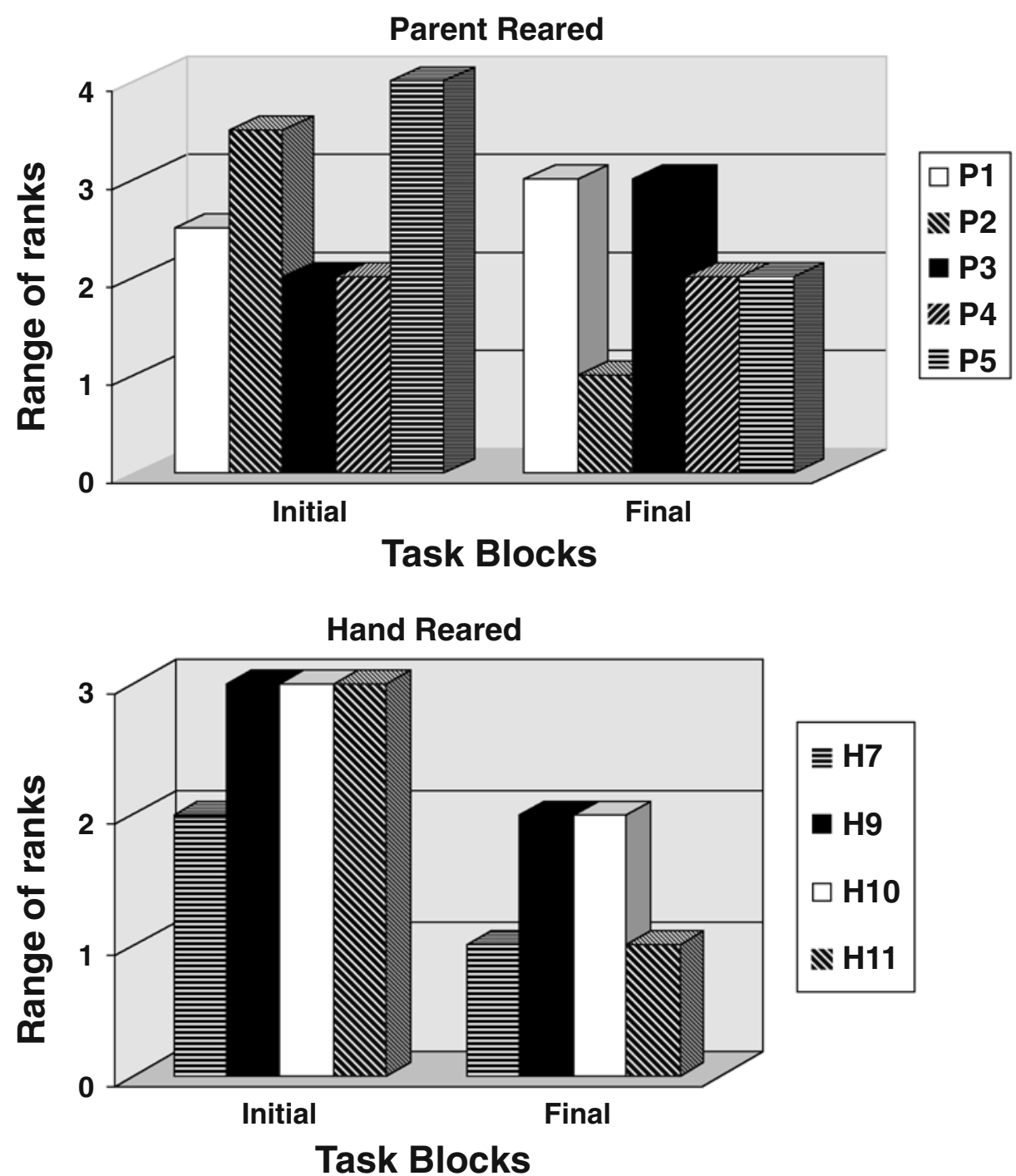

Figure 2. Scale II, means-end: Range of rank orders on blocks of tasks.

derstandable that the impaired birds, P6 and H8, avoided performance more on tasks requiring manipulation. However, the other 3 birds were the same ones that had consistently found handling aversive as nestlings and that later ended up as 3 of the 4 alpha individuals in their groups. When P2 and P3 were taken from the nest box for the first time, both were frightened. P2 struggled, gave distress cries and bit the hand that held her. At 5 weeks of age, P3 was so frightened when he was taken from the nest box that he became immobile for the 5-10 min he was with the investigator. Handling continued to be aversive to both birds. H7, the oldest of the HR group, was 4 weeks old when taken from her parents, and was thus hand-fed the least. She preferred to get what she could from Kiri or feed on the millet and vegetables that the adult female brought into the nest box. A phi coefficient $\left(r_{\phi}\right)$, assessed by a Fisher's exact test, indicated that this early resistance to handling was significantly correlated with the subsequent emergence of dominance status in both groups (Fisher $r_{\phi}=.791, n=9, p=.0476$ ). Also, on the final block of object permanence tasks, we observed that all of the 4 alpha individuals made significantly more errors $(\bar{x}=10$ errors $)$ than did the nondominant birds ( $\bar{x}=6.6$ errors) $\left(r_{\phi}=.80, n=9, p=.040\right)$.

Unstructured tasks: Free play from Scale IV, development of causality. After completion of testing on the other three scales, two tasks from Scale IV involving novel toys (see Testing Environment and Search Items in the Method section) were introduced to allow observation of how subjects reacted during unstructured play. Tops, roly-polys, and wheeled toys were available, along with a string-operated rabbit and a mechanized toy to be manipulated. After a brief demonstration of the toys, most subjects approached and played with the toys. They 


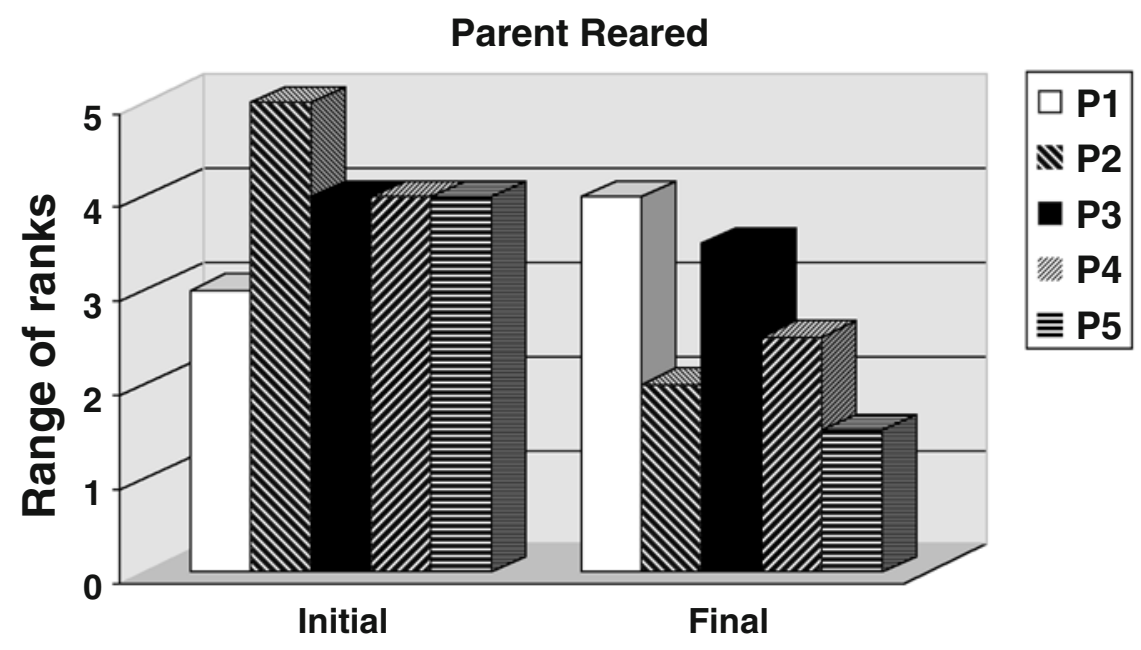

Task Blocks

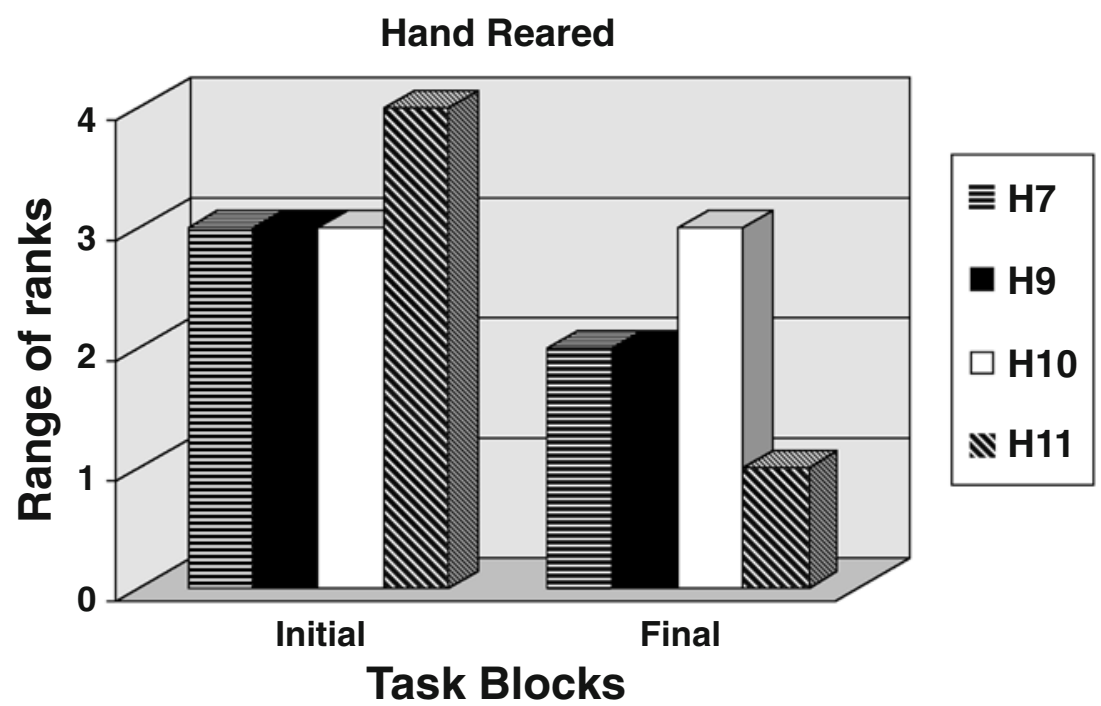

Figure 3. Scale V, spatial relations: Range of rank orders on blocks of tasks.

bit on the string that operated the small rabbit toy, a few of them actually pulling enough to move its arms and legs. After demonstrations of the mechanical rabbit, they applied their beaks or claws to the winder many times, and sometimes the rabbit would move a bit, but they were not able to wind up the toy effectively, and it was not expected that they could do so. The tops and the other moveable toys attracted them also.

Several birds were slow to engage with the toys. P2 and P3 did not even approach any of the toys in their initial session. $\mathrm{H} 7$ and $\mathrm{H} 9$ did not play much with the toys in their first session, and H8 mostly sang, but each of these three did approach and touch a few of the objects and stayed near them, looking at them. These birds all did play with the toys in the two later sessions.

Structured task behaviors. A number of individual birds showed consistency of traits on several behavioral measures. After the early developmental activities, 6 of the birds performed every single day that they were tested; that is, they took no "days off" in which the subject would not perform any of the three tasks presented. The other 5 birds collectively had a total of 9 "days off" during almost 7 months of assessment. Across both groups, alpha female P2 had the highest number of errors on the object permanence scale, and alpha female $\mathrm{H} 7$ had the highest number of avoidances. P2 and $\mathrm{H} 7$ each had 2 "days off" (1.5\% of total sessions for the former and $1.6 \%$ for the latter). P3 made relatively few errors on the object permanence scale, but these errors were concentrated in the final block of tasks, by which time the young male had become uncooperative during the testing. He had the same high avoidance level as P2 on the tasks. H9, the alpha male in his group, was not so reactive as were the other alphas; he had the lowest percentage of avoid- 
ances on all tasks but the highest number of errors on the object permanence scale in his group, and he took 1 "day off" during testing.

For the nonalpha, nonimpaired individuals, only P5 took a "day off" tasks (.08\% of his total sessions). He had an intermediate number of errors, intermediate latencies, and intermediate avoidances. $\mathrm{P} 4$ and $\mathrm{H} 8$ were interactive subjects from early in the testing. P4, at about 7 weeks, partly tracked red yarn in a trajectory, when all others in the group were avoiding even looking at it. H8, however, tracked the syringe filled with food as it was moved in a trajectory above him at 4 weeks, but would track nothing besides the syringe for the next 2 weeks. On the hiding procedures, both of these birds remained attentive and calm, able to follow the targets closely. P1 also was a tamer individual, and he and $\mathrm{P} 4$ were the only individuals who correctly performed all tasks on Scales II and V in their first sessions. They had an intermediate number of errors on Scale I and no "days off." P4 had more avoidances and longer latencies, characteristics typical of the females, and P1 had the shorter latencies and fewer avoidances typical of the males. H10 and H11 had few errors on the object permanence scale; both were attentive subjects, and they had typical percentages of avoidances and latencies for their sex and no "days off."

The impaired birds, P6 and H8, had high avoidances and high latencies on the manipulation tasks (Scales II and V) but low latencies on approach to the toys. H8, who had a minor problem with movement, had no "days off," but P6, who had claw problems, had 3 "days off," all on tasks from the means-end scale that required manipulation of strings or supports. In spite of being the youngest in his group, P6 had the fewest errors in his group on the object permanence tasks, and $\mathrm{H} 8$ had the fewest errors of all subjects.

\section{DISCUSSION}

The present study of yellow-crowned parakeets revealed the emergence of stable individual differences in performance ranks at criterion age on 38 tasks across three cognitive scales: Object permanence, means-end, and spatial relations. These stable rankings were observed in two groups of birds, one parent-reared and the other hand-reared. For each group of birds the criterion age ranks on the final blocks of each of the three cognitive scales were significantly stable and correlated across the three scales. In the very young birds, the initial blocks of tasks most often did not show the stable rank orders in performance seen in the later blocks, after about 13 weeks of age (see Table 2). This instability of ranks in the initial tasks indicated that hatch order was not itself a determining factor of performance rank, even though the dependent variable was mean age at criterion. On all scales, the final ranks generally showed greater stability (Figures 1, 2, and 3) of ranks on the later blocks of tasks than on the initial tasks. This greater variability of ranks seen on the earlier tasks relative to the more stable final ranks supports the developmental emergence of these individual differences in cognitive performance.

\section{Testing Siblings}

It is notable that the subjects were two sets of young siblings who showed stable individual differences on the tests, not just randomly selected individuals who would be more likely to have a variety of reactions to the tests. Verbeek, Drent, and Wiepkema (1994) gathered data on 27 juvenile great tits and siblings, showing that the siblings' reactions to a novel object were more alike than nonsiblings' reactions. Using reactions to the more complex object permanence tasks, however, siblings in the present study ranged from requiring 7 extra sessions to perform tasks (because of errors) to requiring 25 extra sessions (Funk, 1996a), a very wide difference. Fox (1972), who studied four litters of 18 wolves in their responses to different stimuli, also found "wide" intralitter variation, which he suggested helped packs function because of the varied roles the individuals could play in the pack. MacDonald (1983) used unfamiliar objects and other tests with one litter of 5 wolves and again found variability and consistent responses (after 6 weeks). We know from dominance (peck order) studies that in many wild birds raised in sibling groups, individual differences emerge and diversify birds from each other within the developmental environment of their siblings (see discussion in Welty \& Baptista, 1988, pp. 201-211).

The behavioral differences of these related parakeets were remarkable. Despite the hand-rearing of one group, reactions of those individuals varied, with some being more at ease and some more wary during the testing, just as was the case with the parent-reared group. These reactions in some subjects were noticeable when they first left the nest box. Certain of the birds (P1, P4, H8, and H11) would readily and consistently hop on the hand of the investigator when it was time to leave the cage for the testing. In contrast, P2, P3, and H7 were more likely to hang back. For both groups, all the birds had the same parents and were born in the same lab. Nevertheless, across diverse tasks, the parakeets showed individual differences in their performance ranks that were significantly stable on three scales. These statistical data are supported by their behaviors on the testing and their performance on the free-play assessment.

\section{Stable Sibling Ranks After 13 Weeks}

In trying to understand why the birds' ranks should become more stable after 13 weeks, we might examine what developmental milestones occurred around 13 weeks for these captive parakeets (note also discussion of milestones for the grey parrot (Pepperberg, Willner, \& Gravitz, 1997). At 13 weeks, the hand-raised parakeets understood "simple" (Stage 4) object permanence (Scale I, Task 4), a hiding procedure of a reward under one cover. (The grey parrot passed this milestone at 15 weeks.) The parakeets 
could also successfully locate a reward under one of two covers (Scale I, Task 5), but not when the reward was alternated between the covers (Scale I, Task 6; A-not-B error). These results indicate that in the wild, the birds may functionally remember their nest hidden in a tree cavity and likewise recall their siblings, parents, or predators when these others are not present. On Scale II (means-end), Tasks 6-9 were completed around 13 weeks. At this point, the birds should thus be able to pull in food on a support (fruits clustered on leaves) or retrieve fruits hanging on a limb (Funk, 2002). On Scale V (spatial relations), Tasks 5 and 6 were also completed at around 13 weeks. They involved exploring objects and extracting items from containers, which would help in obtaining seeds from pods in the wild (Funk, 1996b). Six or 7 weeks after fledging, parakeets have learned much about the environment, they can procure food, and their social behavior has emerged. Thirteen weeks is probably long enough to develop a characteristic approach for these altricial birds and perhaps for other closely related species, like rosellas.

\section{Declarative Versus Procedural Scales}

This consistency of performance ranks across differing cognitive domains is noteworthy. The three scales, while sharing certain task demands, each also had some distinctive components. All three scales required some degree of attentional focus, perseverance, exploratory and goal-directed behaviors, motor abilities, and response to novel objects or events. In addition, the more declarative object permanence tasks, dealing with factual data, especially required selective attention and short-term memory. The means-end tasks were more procedural, requiring fine manipulative skills, the formulation and maintenance of a goal, and perception of object affordances (Gibson \& Spelke, 1983). Likewise, the procedural aspects of the spatial relations tasks involved more gross visuospatial-motor integration, which underlies skills useful for navigating the environment. Thus, although there is some congruity of processing demands across these three scales, the observed consistencies of individual differences in performance occur in the presence of considerable disparity among these domains. The parakeets' performance showed the effects of these differences in task demands, because both groups completed the means-end and spatial relations scales when they were halfway through the object permanence scale.

\section{Disabilities and Cognitive Performance}

As noted above, two birds had minor physical impairments that impacted their task performance. Thus, their performance was evaluated separately from the core birds on stability ranks. Their physical and/or vocal activity levels were high. Their latencies on manipulatory tasks were the longest in their groups, but when they did eventually engage in tasks their performance was usually quite good. In fact, each of these subjects had the lowest number of errors in his group on the object permanence scale.

The longer latencies in both of these subjects, despite their high activity level otherwise, may have reflected their assessment of their own capability of the task. They could opt to avoid a task if they were unsure of how to correctly proceed (note the discussion of metacognition in pigeons in Fantino, 2003) or if they were conserving energy when unsure that they could physically perform successfully. (Energy budgets are often viewed as an important constraint in foraging: Caraco et al, 1990.) Because of their impairments, these individuals probably had to try even harder than did their siblings; they certainly would have had to do so for survival in the wild.

\section{Individual Differences in Behavior}

Hatch order and task performance. Hatch order was not the determining factor in final performance rankings. This can be seen on Table 2, where, across the three scales, five of the six early blocks of tasks did not show performance ranks coinciding with age order. Ranks were determined primarily by the birds' idiosyncratic performances. For example, P2, who finished last on two of three blocks on the object permanence scale, did not just do poorly at the outset and then stay behind due to that delay, making her end up last: She was only 2 days behind P1 when she finished last on the first block of tasks. She moved ahead of P1 on the next block, but then made more errors (15) than any of the other subjects on the last block. H7, oldest in the HR group, had a similar history. She made fewer errors on the scale than P2, but avoided performance in twice as many sessions (15) as any of the others in either group. P1 actually improved his rank as the testing progressed, and ended as midranked because, although he had second highest number of object permanence errors, he avoided none of the tasks on the last two blocks of 10 tasks and their three repetitions (5 other birds also had no avoidances). The youngest in each group, $\mathrm{P} 6$ and $\mathrm{H} 11$, won their ranks because of their very low number of errors and avoidances on object permanence tasks. Movement in ranks for many subjects on all three scales can be seen in Table 2 .

Avoidance behavior. There are many reasons for avoiding task performance (for a discussion, see Pepperberg \& Funk, 1990). In this study, three of the four alpha individuals were less tractable and cooperative than the other birds. Handling had been aversive to them from the start of testing; perhaps they were genetically still more "wild" than the other siblings. Their avoidances impacted how long it took them to reach criterion, thus affecting their final performance ranks.

Interestingly, in the final block of object permanence tasks, these three high-avoidance alphas showed the greatest number of errors in their groups. The greater error rate by these dominant subjects may reflect a relative impairment under the arousal of the testing situation, as suggested by the Yerkes-Dodson (1908) law, which notes that high arousal has an averse relation with complex 
task performance. This relationship produces an inverted U-shaped function, in which lower performance levels occur when arousal levels are either too high or too low. Thus, the persistent avoidance of handling and testing shown by those 3 alpha individuals may have reflected an arousal level that interfered with information processing on the more difficult tasks that required memory and attention.

\section{Efficacy of Individual Differences in the Wild}

Many researchers have commented on the adaptive nature of individual differences within populations. We know that a variety of traits must be available for selection to operate. Because of the unpredictability in the environment, differences among individuals will be encouraged by selection (Slater, 1981). Behaviors of individuals often depend on what their conspecifics do. For instance, individuals foraging at different times do not compete (Clark \& Ehlinger, 1987), benefiting both individuals and relations within the flock. Also, if some individuals approach quickly and boldly while others take time to look carefully and proceed more cautiously, the latter may (1) note useful cues from the former, (2) have time to note and avoid predators, and (3) find insects stirred up by the others or seeds dropped on the ground, thus locating what has been overlooked earlier, an efficient use of resources. In flocks of birds, such individual styles of foraging could also aid in recognition of individuals, as Skutch (1996) has noted about differing behaviors. Verbeek, Drent, and Wiepkema (1994) point out that birds that are slower to approach may note changes in their surroundings, an important trait when the environment around them is changing.

\section{CONCLUSIONS}

Cognitive as well as motor skills are required to make adaptive changes in the wild because ecological opportunities change constantly. There has been an unstable environment for the yellow-crowned parakeets in New Zealand as their habitat has been modified or lost to wildlife (Taylor, 1985). Piaget, whose early training was as a biologist, thought of cognitive growth as a "specific form of biological adaptation of a complex organism to a complex environment" (Flavell, 1985, p. 4). Using Piagetian tasks, this article demonstrates some of the intraspecific individual differences in cognitive and motor abilities in parakeets that may contribute to relative degrees of success for individuals in their activities in the wild.

Because performance rankings were not directly attributable to the various subject characteristics examined, the rankings most likely reflect a composite of subject factors comprising each unique individual and influencing the perceptual, cognitive, and motor behaviors that determine performance. It is such individual differences within a species that allow maximal exploitation of available opportunities in its niche in the wild.

\section{REFERENCES}

Beauchamp, G. (2000). Individual differences in activity and exploration influence leadership in pairs of foraging zebra finches. $B e$ haviour, 137, 301-314.

Caraco, T., Blanckenhorn, W. U., Gregory, G. M., Newman, J. A., RECER, G., \& ZWICKER, S. M. (1990). Risk-sensitivity: Ambient temperature affects foraging choice. Animal Behaviour, 39, 338-345.

Chaiken, M. (1992). Individual recognition of nestling distress screams by European starlings (Sturnus vulgaris). Behaviour, 120, 139-150.

Clark, A. B., \& Ehlinger, T. J. (1987). Pattern and adaptation in individual behavioral differences. In P. Bateson \& P. Klopfer (Eds.), Perspectives in ethology (Vol. 7, pp. 1-47). New York: Plenum.

Diamond, J. M. (1987). Learned specializations of birds. Nature, 330 , 16-17.

Doré, F. Y., \& Dumas, C. (1987). Psychology of animal cognition: Piagetian studies. Psychological Bulletin, 102, 219-233.

Drent, P. J., van Oers, K., \& van NoordwiJK, A. J. (2003). Realized heritability of personalities in the great tit (Parus major). Proceedings of the Royal Society of London: Series B, 270, 45-51.

FALLS, J. B. (1982). Individual recognition by sound in birds. In D. E. Kroodsma \& E. H. Miller (Eds.), Acoustic communication in birds (Vol. 2, pp. 237-278). New York: Academic Press.

FAnTino, E. (2003). Pigeon parallels to human metacognition. Behavioral \& Brain Sciences, 26, 343-344.

Figueredo, A. J., Cox, R. L., \& Rhine, R. J. (1995). A generalizability analysis of subjective personality assessments in the stumptail macaque and the zebra finch. Multivariate Behavioral Research, 30, 167-197.

Flavell, J. H. (1985). Cognitive development. Englewood Cliffs, NJ: Prentice-Hall.

Fox, M. W. (1972). Socio-ecological implications of individual differences in wolf litters: A developmental and evolutionary perspective. Behaviour, 41, 298-313.

FUnK, M. S. (1996a). Development of object permanence in the New Zealand parakeet (Cyanoramphus auriceps). Animal Learning \& Behavior, 24, 375-383.

FUnK, M. S. (1996b). Spatial skill development in golden-crowned parakeets (Cyanoramphus auriceps): A Piagetian assessment. Bird Behavior, 11, 91-104.

FuNK, M. S. (2002). Problem solving skills in young yellow-crowned parakeets (Cyanoramphus auriceps). Animal Cognition, 5, 167-176.

Gibson, E. J., \& Spelke, E. S. (1983). The development of perception. In P. Mussen (Ed.), Handbook of child psychology (Vol. 3, pp. 1-76). New York: Wiley.

Greene, T. (1988). Behavioural ecology of the red-crowned parakeet and yellow-crowned parakeet on Little Barrier Island. Unpublished master's thesis, University of Auckland, New Zealand.

JUNG, R. E. (1992). Individual variation in fruit choice by American robins (Turdus migratorius). Auk, 109, 98-111.

KaTZIR, G. (1982). Relationships between social structure and response to novelty in captive jackdaws, Corvus monedula L.: I. Response to novel space. Behaviour, 81, 231-263.

MaCDonald, K. (1983). Stability of individual differences in behavior in a litter of wolf cubs (Canis lupus). Journal of Comparative Psychology, 97, 99-106.

Mathieu, M., Daudelin, N., Dagenais, Y., \& Decarie, T. (1980). Piagetian causality in two house-reared chimpanzees (Pan troglodytes). Canadian Journal of Psychology, 34, 179-186.

McGregor, P. K., \& Byle, P. (1992). Individually distinctive bittern booms: Potential as a census tool. Bioacoustics, 4, 93-109.

Norton-Griffiths, M. (1967). Some ecological aspects of feeding behaviour of the oystercatcher Haematopus ostralegus on the edible mussel Mytilus edulis. Ibis, 109, 412-424.

Pepperberg, I. M., \& FunK, M. S. (1990). Object permanence in four species of psittacine birds: An African Grey parrot (Psittacus erithacus), an Illiger mini macaw (Ara maracana), a parakeet (Melopsittacus undulatus), and a cockatiel (Nymphicus hollandicus). Animal Learning \& Behavior, 18, 97-108.

Pepperberg, I. M., Willner, M. R., \& Gravitz, L. B. (1997). Development of Piagetian object permanence in grey parrot (Psittacus erithacus). Journal of Comparative Psychology, 111, 63-75. 
Piaget, J. (1953). Origin of intelligence in the child. London: Routledge \& Kegan Paul.

Piaget, J. (1954). The construction of reality in the child. New York: Basic Books.

Siegel, S., \& Castellan, N. (1988). Nonparametric statistics for the behavioral sciences. New York: McGraw-Hill.

SkUtch, A. F. (1996). The minds of birds. College Station, TX: Texas A\&M Press.

Slater, P. J. B. (1981). Individual differences in animal behavior. In P. Bateson \& P. Klopfer (Eds.), Perspectives in ethology (Vol. 4, pp. 35-49). New York: Plenum.

TAYLOR, R. (1985). Status, habits and conservation of Cyanoramphus parakeets in the New Zealand region. In P. J. Moore (Ed.), Conservation of island birds: Case studies for the management of threatened island species (pp. 195-211). Cambridge: International Council of Bird Preservation. TEN CATE, C. (1992). Coo types in the collared dove Streptopelia decaocto: One theme, distinctive variations. Bioacoustics, 4, 161-183.

Tomasello, M., \& Call, J. (1997). Primate cognition. Oxford: Oxford University Press.

UZGIRIS, I. C. (1987). The study of sequential order in cognitive devel- opment. In I. Uzgiris \& J. M. Hunt (Eds.), Infant performance and experience: New findings with the ordinal scale (pp. 131-167). Urbana: University of Illinois Press.

UzGIRIs, I. C., \& HUNT, J. M. (1967). Ordinal scales of psychological development [Film]. Urbana: University of Illinois Film Center.

UzGIRIs, I. C., \& Hunt, J. M. (1989). Assessment in infancy: Ordinal scales of psychological development (2nd ed.). Urbana: University of Illinois Press.

VAuCLaIR, J. (1996). Animal cognition. Cambridge, MA: Harvard University Press.

Verbeek, R., Drent, P., \& Wiepkema, P. (1994). Consistent individual differences in early exploratory behavior of male great tits. Animal Behaviour, 48, 1113-1121.

Welty, J. C., \& Baptista, L. (1988). The life of birds (4th ed.). Orlando: Harcourt, Brace, Jovanovich.

Yerkes, R. M., \& Dodson, J. D. (1908). The relation of strength of stimulus to rapidity of habit-formation. Journal of Comparative \& Neurological Psychology, 18, 459-482.

ZaR, J. H. (1984). Biostatistical analysis (2nd ed.). Englewood Cliffs, NJ: Prentice-Hall. 


\section{APPENDIX}

Developmental Tasks From Uzgiris and Hunt (1989)

\begin{tabular}{|c|c|}
\hline Task & Task Descriptions (Presentations) \\
\hline \multicolumn{2}{|c|}{ Scale I: Development of Visual Pursuit and Permanence of Objects } \\
\hline 1 & Following a slowly moving object through a $180^{\circ}$ arc (3-4) \\
\hline 2 & Noticing the disappearance of a slowly moving object in trajectory $(3-4)$ \\
\hline 3 & Finding an object which is partially covered (3) \\
\hline 4 & Finding an object which is completely covered (3) \\
\hline 5 & Finding an object completely covered in one of two places (2) \\
\hline 6 & Finding an object completely covered in one of two places alternately (3-5) \\
\hline 7 & Finding an object completely covered in one of three places $(5-7)$ \\
\hline 8 & $\begin{array}{l}\text { Finding an object completely covered in one of three places after successive visible dis- } \\
\text { placements (3) }\end{array}$ \\
\hline 9 & Finding an object under three superimposed screens $(2-3)$ \\
\hline 10 & Finding an object after one invisible displacement (3) \\
\hline 11 & Finding an object following one invisible displacement with two screens (2) \\
\hline 12 & Finding an object following one invisible displacement with two screens alternated (3) \\
\hline 13 & Finding an object following one invisible displacement with three screens $(5-7)$ \\
\hline 14 & Finding an object following a series of invisible displacements (4-6) \\
\hline 15 & $\begin{array}{l}\text { Finding objects after a series of invisible displacements by searching in reverse order of } \\
\text { hiding (2) }\end{array}$ \\
\hline \multicolumn{2}{|c|}{ Scale II: The Development of Means for Obtaining Desired Environmental Events } \\
\hline 1 & Appearance of hand-watching behavior (1) \\
\hline 2 & Achievement of visually directed grasping (3) \\
\hline 3 & Repetitive actions in early play (2) \\
\hline 4 & Letting go of an object to reach for another (3) \\
\hline 5 & Locomotion as means to retrieve an object (2) \\
\hline 6 & Use of the relationship of support (2) \\
\hline 7 & Avoiding choosing unrewarded support (1-2) \\
\hline 8 & Use of string horizontally to retrieve object (2) \\
\hline 9 & Use of string vertically to retrieve object (2-3) \\
\hline 10 & Use of stick as means to obtain object (2) \\
\hline 11 & Foresight in problem of necklace and container (2-3) \\
\hline 12 & Foresight in problem of stacking the solid ring $(2-3)$ \\
\hline \multicolumn{2}{|c|}{ Scale V: The Construction of Object Relations in Space } \\
\hline 1 & Observing two objects alternately $(2-3)$ \\
\hline 2 & Localizing an object by its sound (5-7) \\
\hline 3 & Grasping a visually presented object (2-3) \\
\hline 4 & Following the trajectory of a rapidly moving object (3-4) \\
\hline 5 & Recognizing the reverse side of objects $(2-3)$ \\
\hline 6 & Using the relationship of container and contained $(2-3)$ \\
\hline 7 & Placing objects in equilibrium one upon another (i.e., stacking blocks) (2-3) \\
\hline 8 & Appreciating gravity in play with objects $(2-3)$ \\
\hline 9 & Exploring fall of dropped objects $(1-2)$ \\
\hline 10 & Making detours $(2-3)$ \\
\hline 11 & Indicating absence of familiar persons (1) \\
\hline
\end{tabular}

Note-Numbers in parentheses refer to required trials for all subjects. From Assessment in Infancy: Ordinal Scales of Psychological Development, by I. C. Uzgiris and J. M. Hunt, 1989. Copyright 1975, 1989 by the Board of Trustees of the University of Illinois. Used with permission of the University of Illinois Press. 